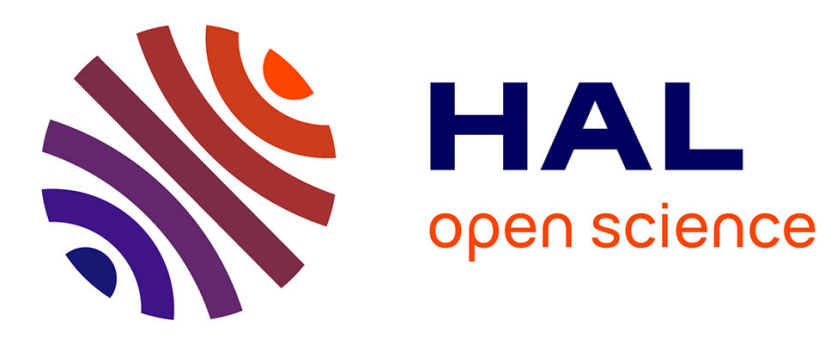

\title{
General analysis of inductive sensor based systems for non destructive testing
}

Isabelle Dufour, Moolraj Busawon, Denis Premel, Dominique Placko

\section{To cite this version:}

Isabelle Dufour, Moolraj Busawon, Denis Premel, Dominique Placko. General analysis of inductive sensor based systems for non destructive testing. Journal de Physique III, 1994, 4 (8), pp.1481-1493. 10.1051/jp3:1994215 . jpa-00249198

\section{HAL Id: jpa-00249198 https://hal.science/jpa-00249198}

Submitted on 1 Jan 1994

HAL is a multi-disciplinary open access archive for the deposit and dissemination of scientific research documents, whether they are published or not. The documents may come from teaching and research institutions in France or abroad, or from public or private research centers.
L'archive ouverte pluridisciplinaire HAL, est destinée au dépôt et à la diffusion de documents scientifiques de niveau recherche, publiés ou non, émanant des établissements d'enseignement et de recherche français ou étrangers, des laboratoires publics ou privés. 


\title{
General analysis of inductive sensor based systems for non destructive testing
}

\author{
Isabelle Dufour ( $\left.{ }^{1}\right)$, Moolraj Busawon ( $\left.{ }^{1}\right)$, Denis Premel $\left({ }^{2}\right)$ and Dominique Placko ( $\left.{ }^{1}\right)$ \\ (') Laboratoire d'Electricité. Signaux et Robotique (LESIR), URA CNRS D1375, Ecole Normale \\ Supérieure de Cachan. 61 avenue du Président Wilson, 94235 Cachan Cedex, France \\ $\left({ }^{2}\right)$ Laboratoire des Signaux et Système (LSS), CNRS-ESE-UPS, Ecole Supérieure d'Electricité, \\ Plateau du Moulon, 91192 Gif-sur-Yvette Cedex, France
}

(Received 20 January 1994, accepted 20 May 1994)

\begin{abstract}
This paper presents a general view of the Non Destructive Testing (NDT) systems based on the use of inductive sensors where the potential users are likely to be more and more numerous. We describe the different phases of their conception. Firstly, we analyse the physical interaction between the sensor and the specimen material by the use of an enlarged concept of electrical Images. The instrumentation problem is next reviewed by analysing the signals which are supplied by these sensors, and by the way leading to the definition of the differing range of applications of such sensors. Finally, we enumerate the various signal processing techniques usually applied in NDT and based on the general inversion techniques.
\end{abstract}

\section{Introduction.}

1.1 The Different TeChNiques of NON DESTRUCTIVE TESTING [1-5]. - The presence of flaws in any type of structure (metals, composites, ceramics..) has necessarily lead to the development of testing techniques which are specially meant to reveal these defects without destroying the integrity of the structure : this is the basic principle of Non Destructive Testing (NDT). These techniques are rather ancient but are in perpetual evolution due to their necessary adaptation to the control of new materials which are nowadays used in the industry and also to account for the technical progress in modelling, signal and image processing. On the other hand, in industrial fields, the NDT are more and more demanded because, in order to optimise the costs of production, the mechanical parts are less over dimensioned and more stressed.

In the figure 1 , the users of these types of testing are briefly listed.

Among the criterion for the decisive choice of the technique to be employed, we note: the physical properties which are influenced by the presence of the defects (namely the electrical 


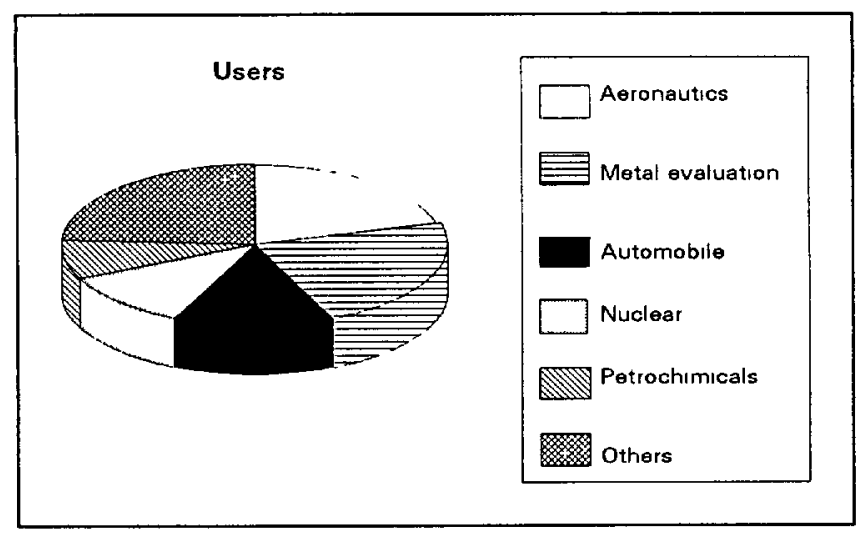

Fig. 1. - Distribution of the users of NDT techniques.

conductivity, the magnetic permeability), the localization of the flaws (superficial, sub-surface or volumetric defects) and the stresses imposed by the environment (single-sided access. no contact with the specimen is possible, the high ambient temperatures, the presence of magnetic fields, no place available for the controlling system). In addition, following the conditions fixed by the manufacturers, one method can be preferred rather than another one: the following cases are to be considered. whether the detection is carried with or without the determination of the properties of the defects, the rapidity of the measurement, the costs of the equipment and the level of qualification of the operators.

The distribution of the different NDT techniques are illustrated in figure 2.

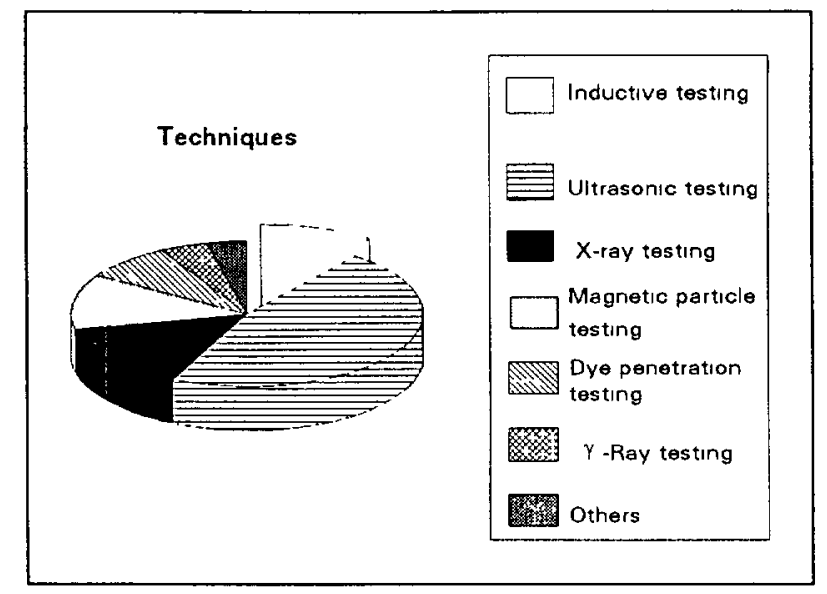

Fig. 2. - Distribution of the NDT techniques.

In the comıng years, the distribution of these techniques will change considerably; specially the ones which will be developed will be the ones where the role of the operator during the testing will be greatly reduced or the operator is completely absent. The NDT methods will be more and more automatic and robotized when the chosen technology will allow it. These 
conditions reveal the important part of the ultrasonic and inductive testing compared to the $\mathrm{X}$ ray radiography, magnetic particle and dye penetration testing where the operator manipulation and observation are predominant and where automatic control becomes more difficult.

1.2 General Method fOR THE DEvelopment of AN NDT SySTEM. - Regardless of the NDT technique to be used, the general method applied for the elaboration of the system can be decomposed in five highly coupled phases (Fig. 3).

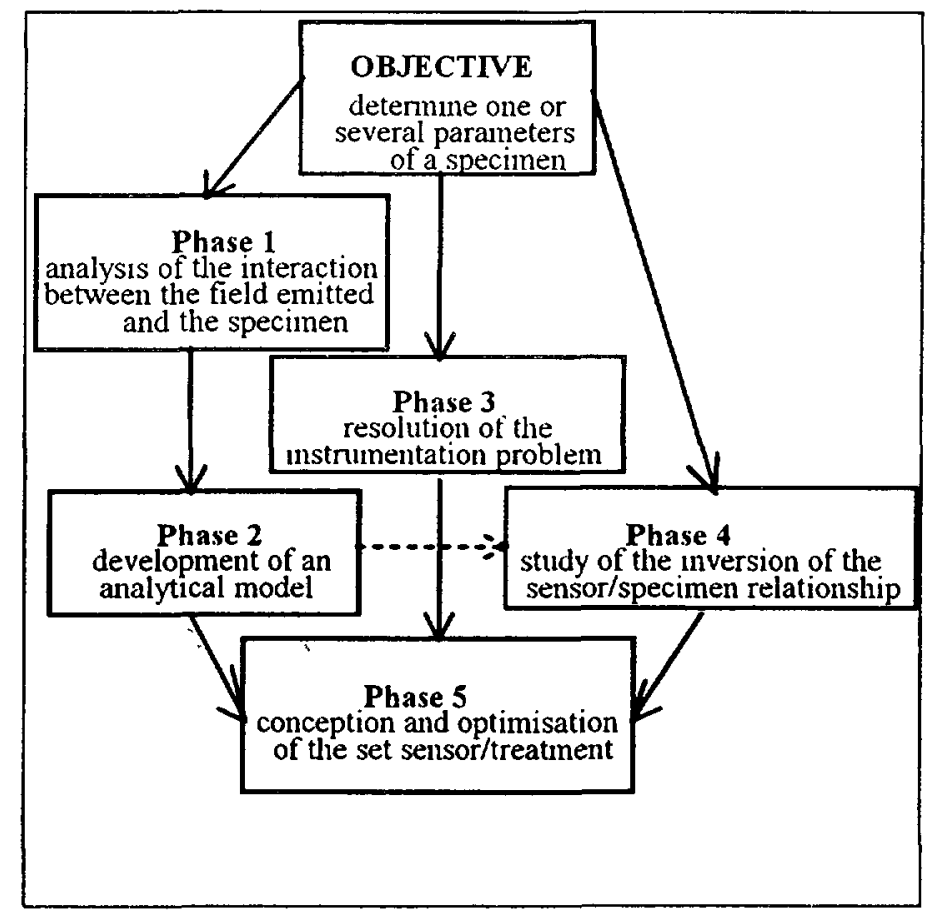

Fig. 3. - Usual methodology for studying and developing an NDT system.

The different sections of the present paper describe every phase of the study, in the case of inductive sensors. This type of reasoning can comply to many criterion when applied to these sensors, where the tests are carried out without contact with the specimen and without having access to both sides. On the other hand, in terms of human security these transducers are interesting because the power used is relatively low and the wavelengths emitted do not necessarily imply to take great precautions for the operator. The main inconvenience of this type of control is linked to the evanescent nature of the wave's propagation in the conducting materials and is a limiting factor for the penetration into the material. Thus, the interpretation of the physical phenomena are difficult and at the same time the signal processing can become too time consuming.

The electromagnetic coupling between the sensor and the material specimen are dealt in phase 1 of the plan and discussed in the paragraph 2.1. The modelling of the sensor/target system (phase 2) is discussed in the paragraphs 2.2 and 2.3 in the case of materials with any electrical conductivity and magnetic permeability. The discussion of the phase 3 is exposed in paragraph 3 where the elaboration of the signals, the domain of application of the sensor are 
studied. At last, in the paragraph 4, the different methods of signal processing for the inversion of the signal emitted by the sensor are enumerated.

\section{Analysis of the sensor/specimen interaction.}

Non Destructive Testing using inductive transducers have been applied since the late $1930^{\circ} \mathrm{s}$ : at that period, the testing was qualitative in nature (whether or not the measured signal crosses a fixed threshold level). In the 1940's and 50's, important progress have been made due to research in the aeronautical and nuclear fields. By the end of the 1950's, the testing with inductive sensors have been effectively applied for the measurement of the electrical conductivity, the detection of surface flaws and afterwards of volumetric flaws [6, 7].

2.1 The General PRINCIPLes OF INDUCTIVE SENSOR OPERATION [8, 9]. - The principle of operation of inductive sensors is based on the laws of electromagnetism and the entire knowledge of the phenomena involved lies on the resolution of the Maxwell's equations. In this section, we will deal with a qualitative description of the physical phenomena.

An inductive transducer can be simply a coil in which is applied an alternative current. This coil is generally winded around a magnetic circuit with the aim of directing the magnetic field in a chosen direction. The magnetic field emitted to the transducer is spread in an area which depends essentially on the sensor geometry : the form of the magnetic circuit is therefore an important element in the conception of inductive sensors (cups, U-shaped magnetic circuits.. ). In the present paper, we deliberately do not detail the choice of the transducer structure, because of the relatively abundant litterature [10-13].

Whenever an electrically conducting and/or magnetic material approaches the influence zone of the sensor, the result is a variation of the topology of field lines together with electromagnetic losses due to the penetration of the magnetic field inside the material.

For non magnetic materials, these two phenomena are simply due to the eddy currents induced by the primary field $H_{\mathrm{p}}$, which in turn create an induced magnetic field $H$, which tends to reduce the induction field $H_{\mathrm{p}}$ (Fig. 4). The eddy currents play a «positive » role in this transducer technology because they are at the origin of the control.

The simplest case to study is the case of highly conducting material to which is associated a high operating frequency. In this type of operation, the transducer is called an eddy current

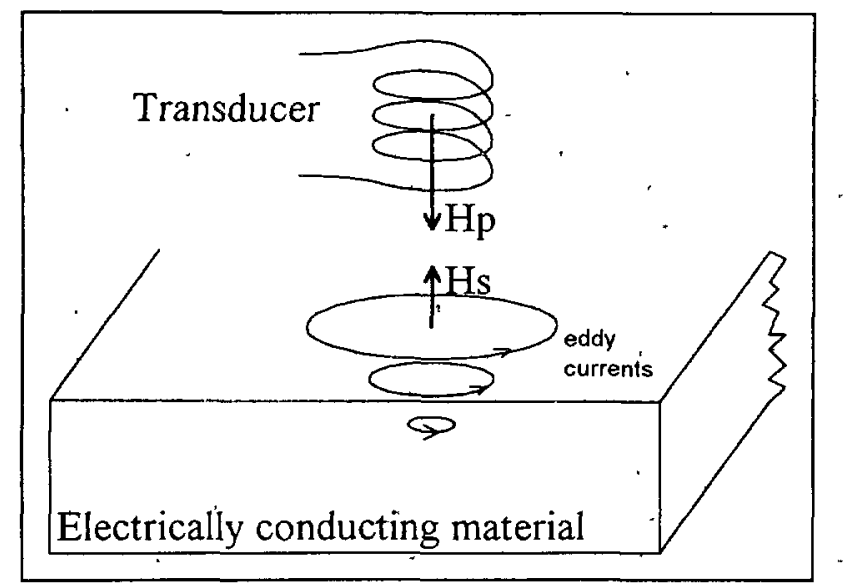

Fig. 4. - Principle of inductive sensors (case of non magnetıc target). 
sensor. Therefore, the field penetration inside the material remains small and the losses are negligible and the limiting boundary conditions whereby the field remains parallel to the surface of the material allows an explanation of the physical phenomenon in terms of electrical images: the transducer and the highly conducting specimen association yields the same magnetic field topology in the sensor-specimen spacing as that produced by the association of two transducers which are symmetrically disposed with respect to the specimen surface; the image sensor emits the same magnetic flux as the real one (Fig. 5) [14-16].

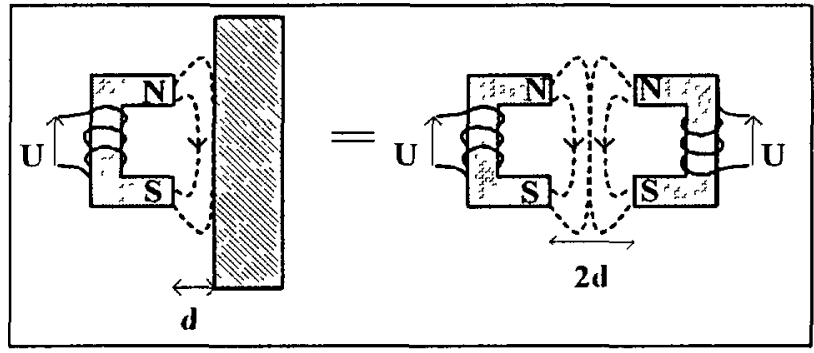

Fig. 5. - Principle of electrical images for a highly conducting material at high excitation frequency.

When the material is highly magnetic and the excitation frequency low, the resulting effect is simply a variation in the topology of the magnetic field lines and can be again explained in terms of electrical images (Fig. 6). In this case, the transducer is called a magnetic sensor. In that particular case, the transducer and the highly magnetic specimen association establishes the same magnetic field topology in the sensor-specimen spacing as that produced by the association of two transducers which are symmetrically disposed with respect to the specimen surface; this time the image sensor emits the opposite magnetic flux as the real one.

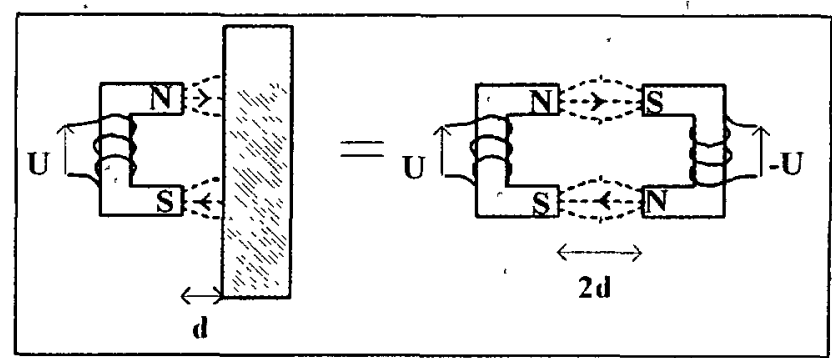

Fig. 6. - Principle of electrical images in the case of a highly magnetic material at low excitation frequency.

In the more general case, where the specimen material is at the same time electrically conducting and magnetic, the physical explanation of the measures will not simply rely on the approximations applied to the geometrical path of the magnetic field lines or the form of the transducer. The distribution of the eddy currents in the material volume and as a result the transducer impedance, noted $Z_{\mathrm{c}}=R_{\mathrm{c}}+j X_{\mathrm{c}}$ in this paper, depend on the following features: 
- firstly on the sensor features : geometry, distance between the specimen and the sensor (lift-off), operating frequency..,

- secondly on the characteristic properties of the specimen : electrical conductivity $\sigma$, magnetic permeability $\mu$, geometrical shape and presence of discontinuities and heterogeneity.

2.2 Physical interaction mOdelling: EXTENSION OF THE CONCEPT OF EleCtrical IMAGES. - Once the analytical expression of the magnetic field in the space between the transducer and the test specimen (with any electrical properties) is known, we are able to extend the concept of electrical images. The detailed analysis is presented in [17] and [18]. The results obtained can be summarized in the following way:

The sensor-specimen system is equivalent to the association of three transducers:

- the real sensor which emits a flux noted $\Phi$;

- a first image sensor which is symmetrical to the real one with respect to the surface of the specimen. This image transducer emits a flux $r \Phi$ with $r=\frac{2 \mu_{r}}{1+\mu_{r}}$

- a second image sensor which is symmetrical to the real transducer with respect to a plane situated at a $\ll$ complex distance $» d+\left(a_{0}\left(\mu_{\mathrm{r}}\right)+j b_{0}\left(\mu_{\mathrm{r}}\right)\right) \frac{\delta}{2}$ from the real transducer where $\left(a_{0}=-b_{0}=\frac{\mu_{\mathrm{r}}+1}{2}\right)$ and $\delta$ is the depth of penetration $\left(\delta=\sqrt{\frac{1}{\pi \mu f \sigma}}\right):$ this transducer emits a flux $p \Phi$ with $p=\frac{1-\mu_{\mathrm{r}}}{1+\mu_{\mathrm{r}}}$

It is to be noted that the factors which are important are the product of the excitation frequency of the transducer by the electrical conductivity of the specimen $(f \sigma)$, the magnetic permeability $\left(\mu_{\mathrm{r}}\right)$ of the specimen and the lift-off $(d)$.

From this general case, we can easily find the two cases presented previously and find other particular cases of operation (Fig. 7) :

- When the electrical conductivity tends to be infinite, $\sigma \rightarrow \infty$, the skin depth of penetration $\delta$ tends to zero. Thus, the two image transducers are coincident and they emit a flux $(p+r) \Phi=\Phi$. The distance between the image transducer and the real one is equal to $2 d$.

- When the magnetic permeability tends to become infinite, $\mu_{r} \rightarrow \infty$, there remains only one image sensor which emits the flux $p \Phi=-\Phi$ (this is due to the expression of $a_{0}$ and $\left.b_{0} \cdot\left(a_{0}\left(\mu_{r}\right)+j b_{0}\left(\mu_{r}\right)\right) \delta \rightarrow \infty\right)$. The spacing between the real sensor and the image sensor is equal to $2 \mathrm{~d}$.

- When the frequency and conductivity product $(f \sigma)$ tends to zero, the skin depth of penetration tends to become infinite and only one image transducer prevails : it emits a flux $p \Phi=\frac{1-\mu_{\mathrm{r}}}{1+\mu_{\mathrm{r}}} \Phi$ and is distant by $2 d$ from the real sensor;

- When the test material is non magnetic, $p=0$ and $r=1$, and there remains only one image sensor : it emits the flux $r \Phi=\Phi$ and is distant by $2 d+(1-j) \delta$ from the real sensor.

2.3 INTEREST OF THIS EXTENSION OF THE NOTION OF ELECTRICAL IMAGES. - With this extended notion of electrical images, it is easy to elaborate an analytical model, for a given sensor geometry, because the association sensor-target can be instantaneously replaced by the association of several similar sensors, with proper excitations and positions.

This analysis is very interesting from two points of view: it gives a good intuitive interpretation of the phenomena, by the use of usual physical principles, and it makes it possible to predetermine accurately the characteristics of the sensor, with regards to a particular application. 


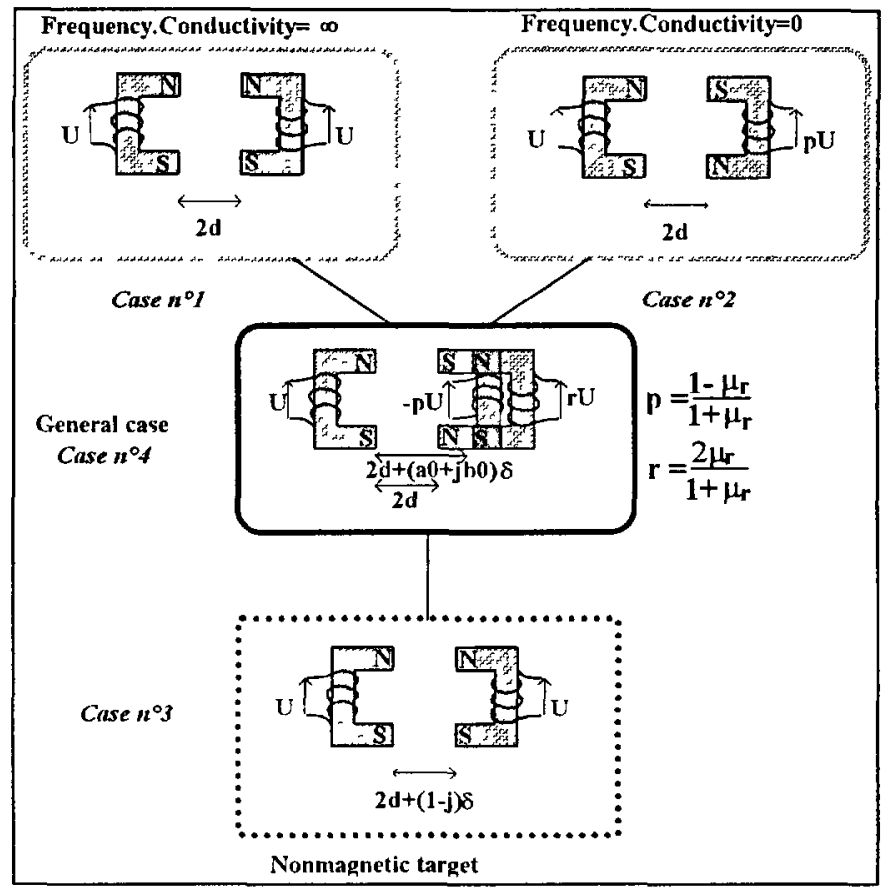

Fig. 7. - Synthesis of the results on the electrical images method.

In fact, with these results. the problem may be reduced to a magnetostatic set of equations : the effect of the approach of a target from the sensor can now be modelled by computing the field radiated by the sensor without the presence of the specimen, and by summing it with the field radiated by image sensors.

Remark: The complex value of the impedance yields from the complex distance term introduced in this extended concept of electrical images.

\section{Resolution of the problem of instrumentation.}

The basic sensor information is generally obtained through the measurement of its coil impedance $Z_{c}$. But. in order to overcome the growth of the reactance with frequency and the existence of sensor losses, the impedance $Z_{c}$ is often normalized to its value without the specimen, $Z_{0}=R_{\mathrm{o}}+j X_{\mathrm{o}}[19-21]$. This normalized impedance, noted $Z_{\mathrm{c} n}$, is defined by:

$$
Z_{\mathrm{cn}}=R_{\mathrm{cn}}+\jmath X_{\mathrm{cn}}=\frac{Z_{\mathrm{c}}-R_{\mathrm{o}}}{X_{\mathrm{o}}}
$$

In figure 8 is presented the aspect of the variations of this impedance in the normalized impedance plane $\left(R_{\mathrm{cn}}, X_{\mathrm{cn}}\right)$ as a function of the distance sensor-specimen and the product signal frequency times electrical conductivity, for a given structure of sensor.

The full and dotted lines represent respectively the case of a magnetic $\left(\mu>\mu_{0}\right)$ and a non magnetic $\left(\mu=\mu_{0}\right)$ target.

In figure 8 , four different operating cases may be defined :

- Case n 1 corresponds to a very high product frequency conductivity. In this case, the normalized impedance is imaginary and depends only on the lift-off (sensor-material distance). 


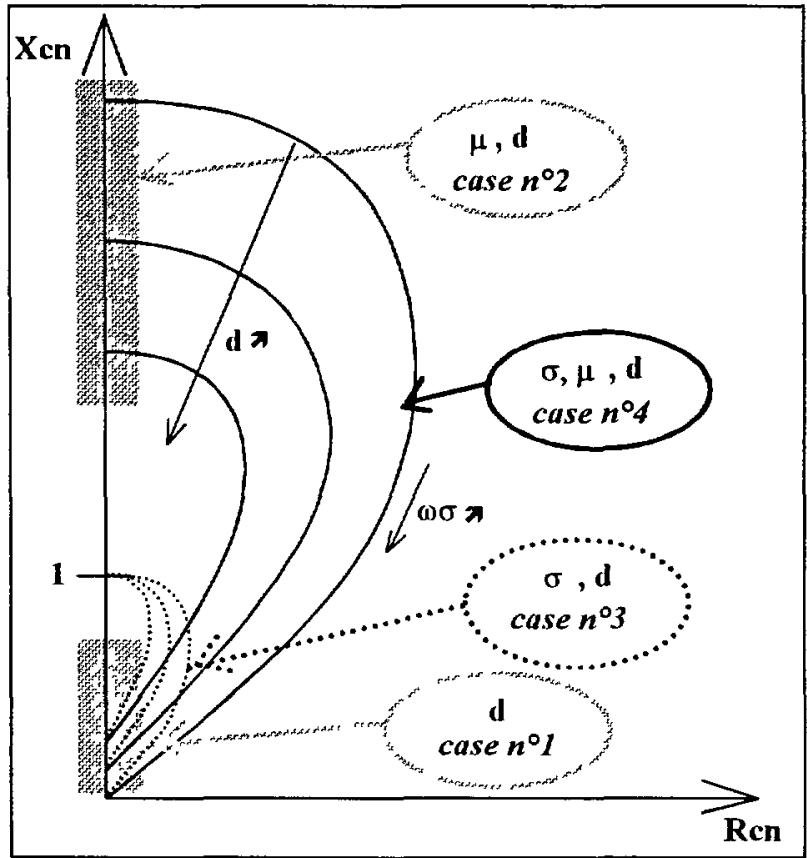

Fig. 8. - Normalized impedance variations.

- Case n 2 corresponds to a very low product frequency conductivity. In this case, the normalized impedance is also imaginary and depends on the sensor-material distance and on the magnetic permeability of the target $\mu_{0} \mu_{\mathrm{r}}$. In the particular case of distance sensor-target equal to zero, the normalized impedance is equal to $j \mu_{\mathrm{r}}$.

- We may note that for a non magnetic target, $\mu_{r}=1$, the normalized impedance is close to $j$, which is the starting point of all the curves obtained for non magnetic materials. In this case $\left(n^{\circ} 3\right)$, for a given frequency, the real and imaginary parts of the normalized impedance depend both on the electrical conductivity of the target and on the distance sensor-target.

- Case $n 4$ corresponds to the general case of a magnetic and conducting target. For a given frequency, the real and imaginary parts of the normalized impedance depend on the electrical conductivity, magnetic permeability of the target and on the distance sensor-target.

As it can be seen in figure 8 , the sensor impedance is dependent on the geometrical and electrical parameters of the material undergoing the test. The sensor structure and operating frequency range can be selected according to a classification of the investigated parameters as shown in figure 9.

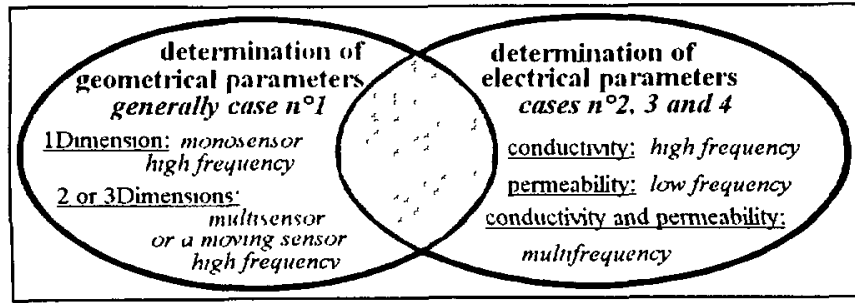

Fig. 9. - Use of inductive sensor. 
The choice of the sensor operation is generally limited to the two simplest cases which respectively represent the working range of case $n 1$ (highly conducting medium and high frequency operation) and case n 2 (test material with high magnetic properties and low test frequency). However, current NDT transducers are meant to operate in the cases numbered 3 and 4 and whereby the interesting NDT information is extracted in the loci of the probe normalized impedance point. These methods are rarely quantitative and any relevant estimation and separation of the tested material characteristics are too often a complicated problem requiring an analytical model.

In the following section, we shall detail some inversion principles which can be readily applied.

\section{Inverse problems.}

4.1 PRESENTATION OF the Signal PROCESSING PROBlem. - Figure 10 recalls the problematic : the sensor signal depends on the tested material parameters and the aim of the signal processing is to estimate one or more parameters with the data given by the measurement system.

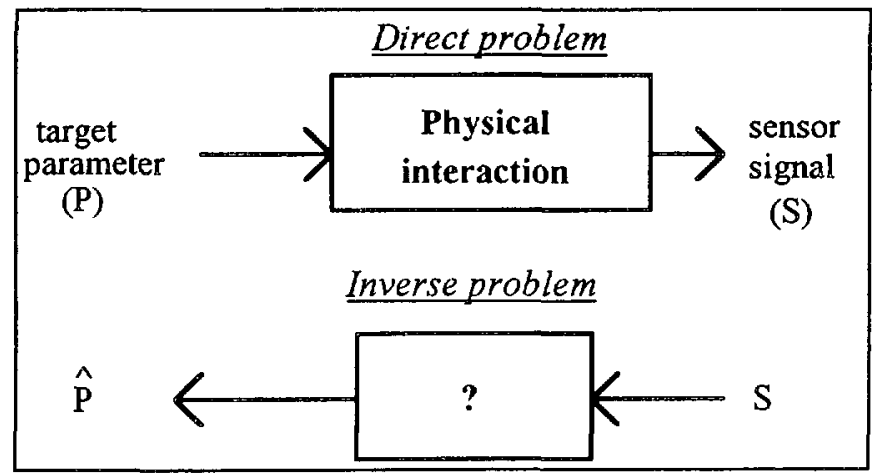

Fig. 10. - Signal processing problem.

In the following sections we describe: first, the inverse methods which need the direct operator $M$ representing the physical interaction and, second the apprenticeship methods which evaluate the experimental interactions in the case of a class of defects which are known a priori.

4.2 RESOLUTION OF THE INVERSE PROBLEM USING DIRECT OPERATOR. - The resolution of the inverse problem needs, first of all. the determination of a model for the resolution of the direct problem which is able to regenerate, synthetically, the signals supplied by the transducer while using a number of parameters which characterize the flawed region. In addition, the complexity of the method of resolution of the inverse problem depends directly on the direct model and the aims to be achieved in characterizing the flawed region.

In practice, we can consider mainly two types of methods : the parametric methods, the imaging methods.

4.2.1 Parametric methods. - The parametric methods, for instance, try to characterize the defect using a few geometrical parameters. The resulting direct model $[22,23]$ is always non- 
linear and a least-squares estimation algorithm is usually sufficient because the number of data observed is higher than the number of parameters to be estimated. The use of such methods are limited in practice because the results become reasonably unacceptable when the geometrical form of the defect does not correspond to the form chosen a priori. Moreover, it is often necessary to determine the geometrical form of the defect.

4.2.2 Imaging methods. - Also, eddy current imaging methods are applied which consist of dividing the defective region using a regular mesh and analysing the NDT problem in the same was as for the tomographic reconstruction problem for heterogeneous media.

4.2.2.1 Qualitative methods. - In the qualitative imaging methods the flaw's contours are reconstructed by estimating the density of the induced currents in all the regular mesh points. The observed data are explicitly related to the eddy current density by a Fredholm integral equation of the first kind whose kernel is invariant by translation along the measuring axis. In the case of planar geometry and by the use of some simplifying hypothesis [24-26] the tomographic reconstruction techniques can allow to restitute the contours of the defects from the image of the induced currents in the inspected conductive material.

4.2.2.2 Quantitative methods. - The quantitative imaging methods reconstruct the spatial distribution of a significant material feature such as the conductivity from the observed data. The direct problem model needs the resolution of the Fredholm integral equation of the second kind and the observed data do not appear explicitly relative to parameters which are to be estimated. The Born approximation is therefore necessary in order to linearize the direct problem, in which case the electric field in the flawed region is very close to the one in the same region which is considered to be homogeneous. The inverse problem is then identical to the inversion of the Fredholm integral equation of the first kind whose kernel is invariant along the measuring axis.

The tomographic reconstruction of the conductive media can be then considered like a Fourier synthesis problem which can be treated by using the Fourier domain or directly in the spatial domain. In the second approach, the problem needs the inversion of a system of linear equations which result from discretising processes in the spatial domain.

The ill-posed character intrinsic to the Fredholm integral equation of the first $k$ ind and the inherent noise that corrupts the measured data impose to regularize the solution. The principle of regularization consists of omitting to solve for the exact solution and to define a class of admissive solutions following an a prorn information such as to obtain an acceptable physical solution. The numerical resolution of the inverse problem becomes the minimization of a mixed criterion containing a term which imposes a good adequation with data and a regularising term which impose the solution to satisfy the a priori information. Two regularizing parameters are chosen to account for the relative importance of these two terms. Several regularizing techniques which are deterministic or stochastic have to be applied in solving satisfactorily the eddy current NDT problem [27, 28].

We note at last that certain methods which are treated in a bayesian approach, have allowed to include a more specific a priori information. Therefore, with this approach more satisfactory solutions have been obtained in the case of a cylindrical geometry having axisymmetrical flaws [29-31].

4.3 RESOLUTIONS OF THE INVERSE PROBLEM WITHOUT THE KNOWLEDGE OF THE DIRECT OPERATOR. - At last, whenever no models are available, methods of adaptative learning are derived which consist of establishing a set of relationships which in turn evaluate the investigated parameters from the sensor signals obtained experimentally in the calibration phase. Linearization principles are then commonly applied [32] and the relationships existing between the parameter and the useful signal are extracted by means of a globally memorised 


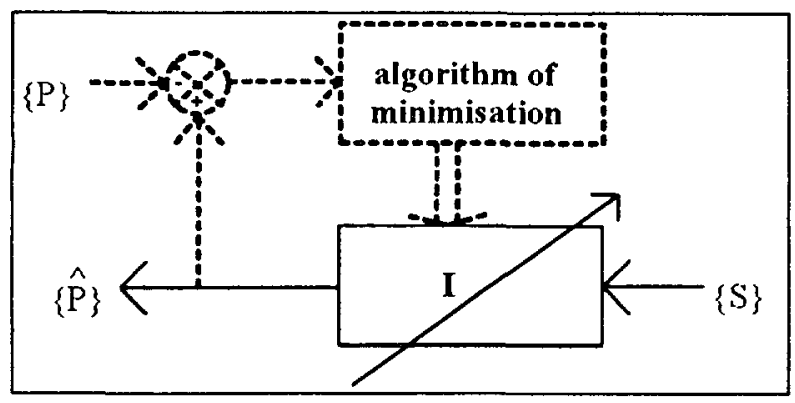

Fig. 11. - Direct research of the inverse operator.

curve or some significant coefficients which are previously resultant of a calibration or apprenticeship phase (Fig. 11).

This case consists of measuring in the experimental conditions the normalized impedance points $Z_{\mathrm{cn}}$ (signal $\mathrm{S}$ ) while varying the required parameters $P$ such as lift-off, electrical conductivity $\sigma$, magnetic permeability $\mu_{r}$, or standard flaw dimensions. This set of parameters is approximated in a polynomial form :

$$
[P]=f(S)=\sum_{11}^{\prime 2} a_{n} S^{\prime} .
$$

This polynomial can be expressed in a matrix from as follows :

$$
[P]=[I][A]
$$

where $[A]$ is a vector matrix relating the $[I]$ matrix to the relevant parameters $[P]$.

In practice, the matrix $[I](m \times n$ matrix, $m>n)$ is singular or noninversible and rank deficient due to floating point errors in calculating the elements of the matrix and random noise included during the experimental apprenticeship phase. Some of the columns are linearly dependent by the nature of the problem modelled by the above matrix expression.

The rank $(I)$ is considered to be less than $n$, that is, some singular values of [I] are considered to be negligible or zero; in this way the columns are rendered linearly independent. Therefore it seems reasonable to replace the matrix expression by a matrix of lower rank and then proceed with a least-squares solution $\left[A_{c}\right]$ of the system, since the distance from $[I]\left[A_{c}\right]$ to $[\mathrm{P}]$ is as small as possible.

We observe that :

$$
[\hat{P}]=[I]\left[A_{\mathrm{c}}\right]=\left(\left[I^{\prime}\right][I]\right)^{-1}\left[I^{\prime}\right][P][I]
$$

is the projection of $[P]$ onto $[I]$ or equivalently, the projection of $[P]$ onto the subspace of $R^{\text {runh (I) }}$ spanned by the columns of $[I]$ is the vector $R^{\text {runh (I) }}$ in closest to $[P]$ (notation : $R^{\prime \prime}$ denote the set of column vectors with $n$ real entries)

$$
[\hat{P}]=\operatorname{proj}_{1}[P]
$$

\section{Conclusion.}

A general view of the Non Destructive Testing system using inductive sensors is presented together with the potential industrial use. The analysis of the physical interaction between the 
sensor and the tested material is exhaustive in the sense that all the relevant material properties have been included. This presentation has allowed the use of the concept of electrical images (which is not currently applied) and the establishing of different ranges of applications of such transducers as a function of the working frequency, the electrical conductivity and the magnetic permeability of the specimen. The final phase in the conception of the inductive NDT system is the signal processing which reveals the desired parameters : in this connection, we have reviewed the general methods used.

\section{References}

[1] «Traitement de l'information et contrôles non destructifs", Proceedings of the « Journées d'étude (COFREND et SEE) 》 (September 1992) Gif-sur-Yvette. France.

[2] «Les contrôles non destructıfs : généralité », Cahıer de formation du CETIM, 2r édition (1991) 100 pages.

[3] Colomer J., Essai de synthèse des méthodes de contrôle non deștructif, Rev. Pratique Contrôle Industriel Qualté, n 161 bis (March 1990) 23-27.

[4] Forest G., Cho1x d'une méthode de contrôle (édition Afnor, 1992).

[5] Peyrucat J. F., Le contrôle non destructif, Mesures (February 1992) 62-65.

[6] Shaffer R. D., Historical development of eddy current testıng in aircraft maintenance, Mater. Evaluation (January 1992) 76.

[7] Hagemaier D. J., Applications of eddy current testing to airframes, in Nondestructive testing handbook, 2nd Ed., vol. 4. Electromagnetic testing. Paul McIntire and Michael L. Mester Eds., American society for nondestructive testing, Inc., Columbus, OH (1986) pp. 369-420.

[8] Libby H. L., Introduction to electromagnetic nondestructive test methods (Robert E. Krieger Publishing Company, reprint 1979).

[9] McMaster R., Udpa S., "Basic concepts and theory of eddy current testing », in Nondestructive testing handbook, 2nd Ed.. vol. 4, Electromagnetic testıng. Paul McIntire and Michael L. Mester, Eds., American society for nondestructive testıng. Inc., Columbus, OH (1986) pp. 25 51 .

[10] Ida N.. "Eddy current transducer", in Nondestructive testing handbook, 2nd Ed., vol. 4, Electromagnetic testıng. Paul McIntire and Michael L. Mester Eds., American society for nondestructive testıng, Inc., Columbus, OH (1986) pp. 53-88.

[11] Vernon S. N., Eddy current probe design for anisotropic composites, Mater. Evaluation (January 1992) 36-41.

[12] Placko D.. Dufour I., A focused field eddy current sensor for nondestructive testing, IEEE Trans. Magn. 29 (1993) 3192-3194.

[13] Dufour I., Placko D.. Geoffroy M., Active shielding : an original method to improve eddy current sensor performances, submitted to the $J$ Phys. D Applied Physics (November 1993).

[14] Gardıol F.. Electromagnétisme. Tratté d'électronique et d'électrotechnique (Edition Dunod, 1987) pp. 72-73.

[15] Lorrain P., Corson D. R., Champs et ondes électromagnétıques (Edition A. Colin) pp. 165-178.

[16] Placko D., Contribution à la conception de capteurs inductıfs pour la robotique industrielle, Rapport de synthèse pour l'habılitatıon à diriger des recherches en sciences, Université de Paris XI. Orsay, France (22 mai 1990).

[17] Dufour I.. Contribution à l'évolution des procédés de contrôle non destructıf par capteurs inductıfs : application au cas des matériaux composites carbone, Thèse de docteur en sciences de l'Unıversité de Paris XI, Orsay, France (28 avril 1993).

[18] Dufour I., Placko D., Generalisation of the electrical image theory through an analytical study of inductive sensors, submitted to IEEE Trans Magn. (July 1993).

[19] Förster F., « Analysıs of encircling coil tests of wire, rods and bars », in Nondestructıve testing handbook, 2nd Ed., vol. 4, Electromagnetic testing. Paul McIntire and Michael L. Mester Eds., American society for nondestructive testing, Inc., Columbus, OH (1986) pp. 111-145. 
[20] Valleau A. R., Eddy current nondestructive testing of graphite composite materials, Mater. Evaluation (February 1990) 230-239.

[21] Vernon S. N., A single sided eddy current method to measure electrical resistivity, Mater Evaluation (November 1988) 1581-1587.

[22] Auld B. A.. Muennman F. G.. Riaziat M.. Quantitative modelling of flaw responses in eddy current testing, Nondestructive Testing n 7 (1984) 37-76.

[23] Ratnajeevan S., Hoole H., Inverse problem methodology and finite elements in the identification of cracks, sources, materials, and their geometry in inaccessible locations, IEEE Trans. Magn. 27 (1991) 3433-3443.

[24] Zorgati R., Imagerie par courants de Foucault. Applıcation au contrôle non destructif, Thèse de 1'Université de Paris VII, Paris, France (1990).

[25] Zorgati R., Duchene B., Lesselier D., Pons F., Eddy current testing of anomalies in conductıve materials. Part 1: qualitatıve imaging va diffraction tomography techniques, IEEE Trans Magn. 27 (1991) 4416-4437.

[26] Nikolova M., Tomographie des diffractions par courants de Foucault pour le contrôle non destructif, Rapport L2S, Gif-sur-Yvette (1991).

[27] Sabbagh H. A., Radecki D. J., Barkeshli S., Shamee B., Treece J. C., Jenkins S. A., Inversion of eddy current data and reconstruction of three dimensional flaws. IEEE Trans Magn. 26 (1990) 626-629.

[28] Zorgati R., Duchene B., Lesselier D., Pons F., Eddy current testing of anomalies in conductive materials, Part 2 : quantitative imaging via determinıstic and stochastıc inversion techniques, IEEE Trans Magn. 28 (1992) 1850-1862.

[29 Premel D., Djafari A. M., David B., « Tomographı par courants de Foucault », Proc. Actes du premıer congrès COFREND sur les essais non destructifs. Nice, France (1990) pp. 415-419.

[30] Premel D., Djafarı A. M., David B., «Imagerie des mılieux conducteurs par courants de Foucault », Actes du treızième colloque GRETSI, Juans les Pins, France (1991) pp. 105-108.

[31] Premel, «Imagerie tomographique des milieux conducteurs par courants de Foucault : application au contrôle non destructif des tubes métalliques », Thèse de docteur en sciences de l'Université de Paris XI, Orsay. France (16 décembre 1992).

[32] Aknin P., Monteil F., Placko D., Modélisation d'une structure multicapteur à courants de Foucault destinée à l'analyse de profil, Rev'. Phvs. Appl 24 (1989) 227-242. 